Journal of Mathematics and Statistics 8 (1): 144-149, 2012

ISSN 1549-3644

C 2012 Science Publications

\title{
Application of Cubic Spline in the Implementation of Braces for the Case of a Child
}

\author{
${ }^{1}$ Rokiah Rozita Ahmad, \\ ${ }^{2}$ Najah Ghazali, ${ }^{1}$ Azmin Sham Rambely, \\ ${ }^{1}$ Ummul Khair Salma Din and ${ }^{1}$ Nasruddin Hassan \\ ${ }^{1}$ School of Mathematical Sciences, Faculty of Science and Technology, \\ University Kebangsaan Malaysia, 43600 UKM Bangi, Selangor DE, Malaysia \\ ${ }^{2}$ Institute of Engineering Mathematics, Universiti Malaysia Perlis, \\ 02000 Kuala Perlis, Perlis, Malaysia
}

\begin{abstract}
Problem statement: Orthodontic teeth movement is influenced by the characteristics of the applied force, including its magnitude and direction which normally based on the shape of ellipsoid, parabolic and U-shape that are symmetry. However, this will affect the movement of the whole set of tooth. Approach: This study intends to compare the form of general teeth with another method called cubic spline to get a minimum error in presenting the general form of teeth. Cubic spline method is applied in a mathematical model of a child's teeth, which is produced through resignation of orthodontic wires. It is also meant to create a clear view towards the true nature of orthodontic wires. Results: Based on mathematical characteristics in the spline and the real data of a teeth's model, cubic spline shows to be very useful in reflecting the shape of a curve because the dots chosen are not totally symmetry. Conclusion/Recommendation: Therefore, symmetrical curve can be produced in teeth's shape which is basically asymmetry.
\end{abstract}

Key words: Cubic spline method, orthodontic, mathematical minimum error

\section{INTRODUCTION}

Dental braces (also known as orthodontic braces or simply braces) are a device used in orthodontics to align teeth and their position with regard to a person's bite. They are often used to correct malocclusions such as under bites, overbites, cross bite and open bites, or crooked teeth and various other flaws of teeth and jaws, whether cosmetic or structural. Teeth move through the use of force. The force applied by the arch wire pushes the teeth in a particular direction and a stress is created with less pressure within the periodontal ligament. Therefore, many patients who did orthodontic treatment will use it for almost two years.

Teeth will usually move about a millimeter per month during orthodontic movement, but there is high individual variability. Orthodontic mechanics can vary in efficiency, which partly explains the wide range of response to orthodontic treatment.

\section{MATERIALS AND METHODS}

Application of Braces via Mathematical Concepts: The teeth, brackets, bands and the arch wire, can be constructed based on a coordinate system. It was deemed appropriate to ascertain the mathematical nature of the relationship and devise a computer based graphics system for producing templates of the arch wire. An orthodontic arch wire is fitted through the brackets and the results are displayed using computer graphics. The points are marked to evaluate the constant relationship among teeth and orthodontic brackets to which an arch wire is adapted.

The new position of teeth after using arch wire will be predicted using mathematical modeling. Since the assumption was made that all digitized points should fall on the curve because they were considered to represent arch form, any normal of length not equal to zero was considered to represent error in fit of the spline.

It is anticipated that the model of teeth arch would be useful in the orthodontic clinical setting as an aid in arch wire formation. The graphics of the model produce a template which incorporates essential points to consider in arch wire formation, namely, perimeter length, lateral widths, symmetry and appropriate arch form for the patient.

At the same time, bracket that has been fixed will exert pressure at various level depends on the gap 
between the teeth and its ideal position. Mathematical model approach is also utilized to ascertain the positon of wire arc. The wire arc is moulded to achive the new conformation which satisfy a perfect teeth model, while at the same time maintain certain position of teeth that are deemed normal and stable.

Application of Cubic Spline method: Orthodontic teeth movement is influenced by the characteristics of the applied force, including its magnitude and direction and the physiological condition of the periodontal tissue of individual patients. However, researches carry out on teeth treatments in clinics indicated no sign of application of this mechanical theory. What really happens is that dentists compare the actual teeth conformation and the perfect one to confer the braces. In this study, analysis of dental arches conformation could be done through cubic spline method.

Spline is a common curve used in this field not just easy to solve, but also due to its concise trial and accessibility in forming equation. Furthermore, it is fully able to trace the rough complex through alignment of straight line curve and interactive arc design (Chapra and Canale, 2002).

This simulation method was based on two assumptions: (1) the neutral surface passed through the center of the cross section of orthodontic wires and (2) the curvature of the teeth was not exactly symmetric to both right and left teeth.

Many authors, including Mills and Hamilton (1965), Biggerstaff (1972), Currier (1969) and Hechter (1978) have used a parabola of the form $x^{2}=-2$ py to describe the shape of dental arches. By using $p=2.5$, which is the width of the teeth frame, the equation was formed as in Fig. 1.

Others, like Pepe (1975) have examined a catenary curve of the form $y=\frac{e^{x}+e^{-x}}{2}$ as a means of describing arch form as in Fig. 2 (Lyew, 1998).

Others, including Izard (1927), Biggerstaff (1972) and Currier (1969), have suggested the use of ellipse shape of the form $\frac{x^{2}}{b^{2}}+\frac{y^{2}}{a^{2}}=1$. Values of $b$ and a refer to the maximum length and width of the teeth model. By taking the value of $a=14.8225$ and $b=5$, the general dental conformation is obtained as in Fig. 3. (Lyew, 1998)

Common similarity among these methods was the mathematical symmetry present in the geometric figures obtained as a representation of arch form.

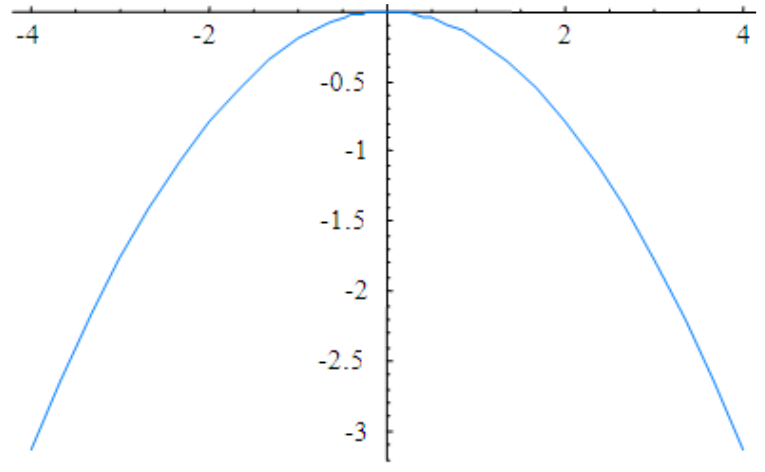

Fig. 1: Parabola

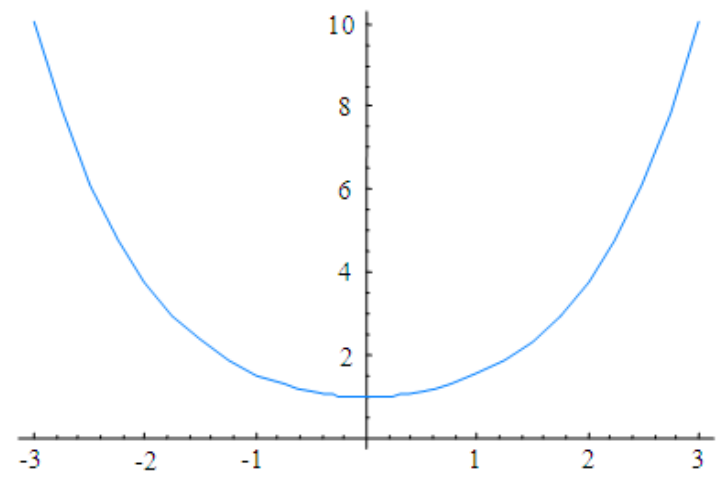

Fig. 2: Catenary

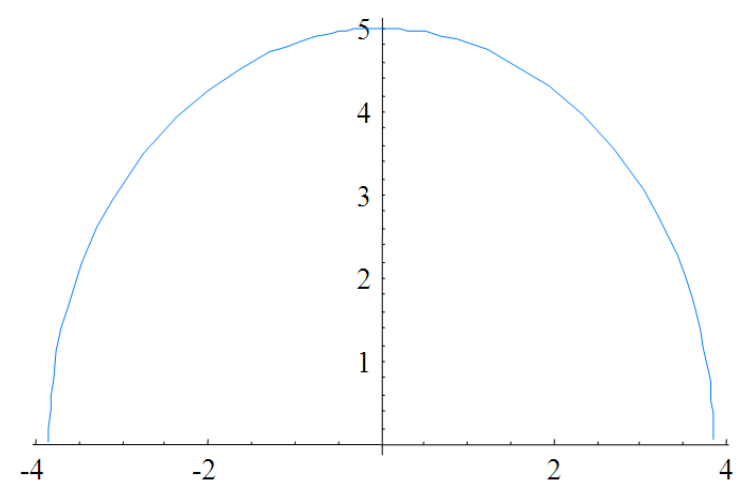

Fig. 3: Elips

However, several author including Pepe (1975) and Hetcher (1978) have concluded that symmetry of the dental arches is not necessarily present in the average or normal occlusion. Hechter found that if an asymmetric arch were made symmetric by orthodontic treatment, this, like other dental variables, tended to return to its pretreatment status. 


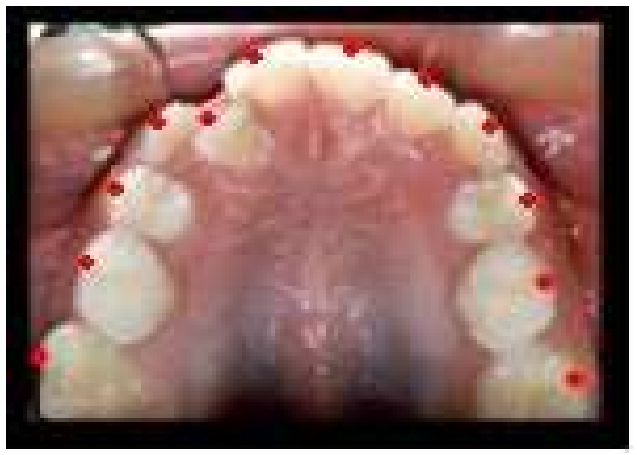

Fig. 4 : Neutral points plotted on each teeth

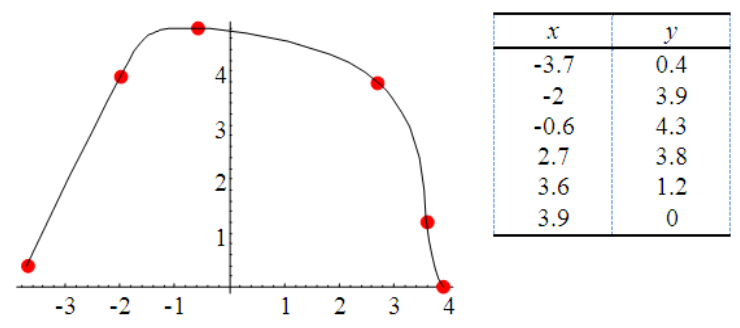

Fig. 5: Six points plotted
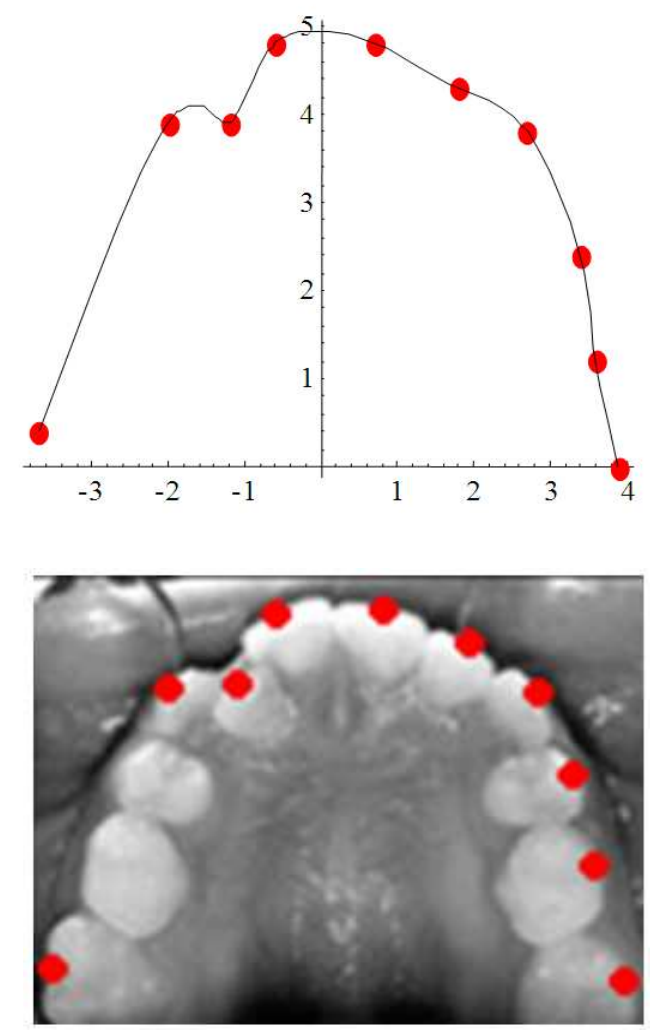

Fig. 6: Points plotted based on actual teeth.

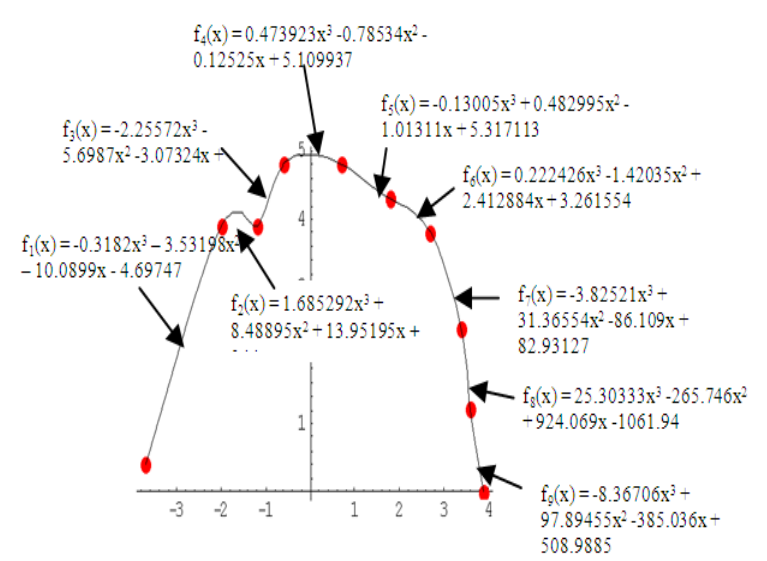

Fig. 7: Spline cubic equation at each interval

Table 1: Data for the point of the teeth

\begin{tabular}{lrrrrrrrrrl}
\hline $\mathrm{x}$ & -3.7 & -2 & -1.2 & -0.6 & 0.7 & 1.8 & 2.7 & 3.4 & 3.6 & 3.9 \\
\hline $\mathrm{y}$ & 0.4 & 3.9 & 3.9 & 4.8 & 4.8 & 4.3 & 3.8 & 2.4 & 1.2 & 0 \\
\hline
\end{tabular}

It seems reasonable as the purpose of this study to use an asymmetric function, the cubic spline, to describe the dental arches. The dental confirmation of a 6 years old child was taken as a sample. It was then plotted on a graph paper to obtain the position of two dimension point. Table 1 indicates the data collected from the sample in Fig. 4.

Spline curve will varies when different point are taken from the same teeth data. See the points and spline curve formed in Fig. 5.

As the spline curve varies with the position of the points, it is essential to choose the points which best complement the conformation of the teeth been analyzed. Figure 6 portrayed a spline curve which is closely identical to the actual teeth conformation.

By utilizing cubic spline method, the dental conformation can be formulated into mathematical equation as shown in Fig. 7.

Refer to Fig. 6 (Cheney and Kincaid, 2007). Spline method is able to portray a smooth, accurate shape which is closely indentical to the actual teeth condition. In order to improve the teeth arrangement, the same method can be applied to predict a better, wellorganized conformation which keeps amount of change been made at the least.

Figure 7 Shows five fixed points with four intervals produced.

Cubic spline method used 5 points as in Fig. 8 in order to get a better dental conformation. Assumption was made that after bracket is applied, the teeth position will change according to the bracket's shape. This shape ascertains a minimum range of change been made Fig. 9. Polynomial s, $\mathrm{x}$ can be determined by using cubic spline formula as follows: 


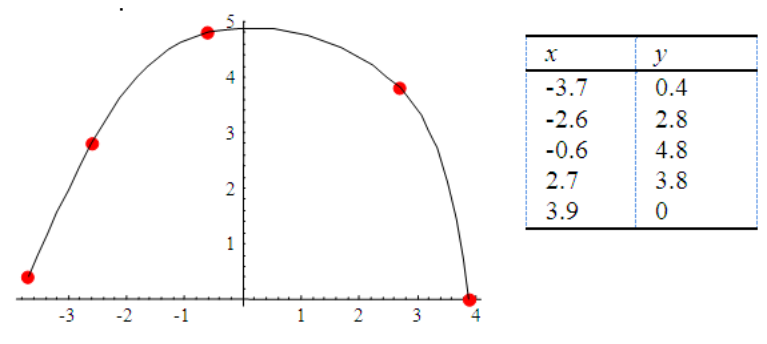

Fig. 8: Five points plotted

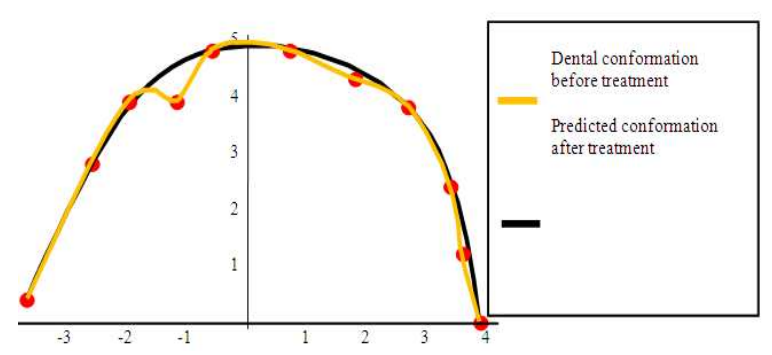

Fig. 9: Dental conformation before treatment and predicted conformation after treatment

$$
\begin{aligned}
f_{3 i}(x) & =\frac{f^{\prime \prime}\left(x_{i-1}\right)}{6\left(x_{i}-x_{i-1}\right)}\left(x_{i}-x\right)^{3}+\frac{f^{\prime \prime}\left(x_{i}\right)}{6\left(x_{i}-x_{i-1}\right)}\left(x-x_{i-1}\right)^{3} \\
& +\left[\frac{f\left(x_{i-1}\right)}{x_{i}-x_{i-1}}-\frac{f^{\prime \prime}\left(x_{i-1}\right)\left(x_{i}-x_{i-1}\right)}{6}\right]\left(x_{i}-x\right) \\
& +\left[\frac{f\left(x_{i}\right)}{\left(x_{i}-x_{i-1}\right)}-\frac{f^{\prime \prime}\left(x_{i}\right)\left(x_{i}-x_{i-1}\right)}{6}\right]\left(x-x_{i-1}\right)
\end{aligned}
$$

with satisfies the following conditions Eq. 1 and 2:

$$
\mathrm{f}^{\prime},\left(\mathrm{x}_{0}\right)=\mathrm{f}^{\prime},\left(\mathrm{x}_{\mathrm{n}}\right)=0
$$

In order to develop 1 the value for derivative of i-1 and $i$ can be dictated by solving 2 given below

$$
\begin{aligned}
& \left(x_{i}-x_{i-1} f^{\prime \prime}\left(x_{i-1}\right)+2\left(x_{i+1}-x_{i-1}\right) f^{\prime \prime}\left(x_{i}\right)+f^{\prime \prime}\left(x_{i+1}\right)\left(x_{i+1}-x_{i}\right)\right. \\
& =\frac{6}{\left(x_{i+1}-x_{i}\right)}\left[f\left(x_{i+1}\right)-f\left(x_{i}\right)\right]+\frac{6}{\left(x_{i}-x_{i-1}\right)}\left[f\left(x_{i-1}\right)-f\left(x_{i}\right)\right]
\end{aligned}
$$

By using the formula, it is known that:

$$
\mathrm{f}^{\prime},\left(\mathrm{x}_{0}\right)=\mathrm{f}^{\prime},\left(\mathrm{x}_{10}\right)=0 \text {. }
$$

Gauss-Seidel method were used in order to solve the value for $\mathrm{f}^{\prime}$ ' $\left(\mathrm{x}_{1}\right), \mathrm{f}^{\prime}$ ' $\left(\mathrm{x}_{2}\right) \ldots \mathrm{f}$ '' $\left(\mathrm{x}_{9}\right)$ :

$$
\left(\begin{array}{cccccccc}
5 & 0.8 & 0 & 0 & 0 & 0 & 0 & 0 \\
0.8 & 2.8 & 0.6 & 0 & 0 & 0 & 0 & 0 \\
0 & 0.6 & 3.8 & 1.3 & 0 & 0 & 0 & 0 \\
0 & 0 & 1.3 & 4.8 & 1.1 & 0 & 0 & 0 \\
0 & 0 & 0 & 1.1 & 4 & 0.9 & 0 & 0 \\
0 & 0 & 0 & 0 & 0.9 & 3.2 & 0.7 & 0 \\
0 & 0 & 0 & 0 & 0 & 0.7 & 1.8 & 0.2 \\
0 & 0 & 0 & 0 & 0 & 0 & 0.2 & 1
\end{array}\right)\left(\begin{array}{c}
\mathrm{f}^{\prime \prime}(-2) \\
\mathrm{f}^{\prime \prime}(-1.2) \\
\mathrm{f}^{\prime \prime}(-0.6) \\
\mathrm{f} "(0.7) \\
\mathrm{f}^{\prime \prime}(1.8) \\
\mathrm{f}^{\prime \prime}(2.7) \\
\mathrm{f}^{\prime \prime}(3.4) \\
\mathrm{f}^{\prime \prime}(3.6)
\end{array}\right)=\left(\begin{array}{c}
-210 / 7 \\
9 \\
-9 \\
-30 / 11 \\
-20 / 33 \\
-26 / 3 \\
-24 \\
12
\end{array}\right)
$$

$$
\left(\begin{array}{c}
\mathrm{f}^{\prime \prime}(-2) \\
\mathrm{f}^{\prime \prime}(-1.2) \\
\mathrm{f}^{\prime \prime}(-0.6)
\end{array}\right)=\left(\begin{array}{c}
-3.2456 \\
4.8438 \\
\mathrm{f}^{\prime \prime}(0.7) \\
\mathrm{f}^{\prime \prime}(1.8) \\
\mathrm{f}^{\prime \prime}(2.7) \\
\mathrm{f}^{\prime \prime}(3.4) \\
\mathrm{f}^{\prime \prime}(3.6)
\end{array}\right)=\left(\begin{array}{c}
-3.2768 \\
0.4198 \\
-0.4385 \\
0.7626 \\
-15.3033 \\
15.0607
\end{array}\right)
$$

For the 10 points there are nine unique polynomial of degree three that passed through all points. There are nine equations that have been developed through $\mathrm{f}$ ' $(x)$ and all the points given as in 1 .

The summation of normal can be found by derivative towards spline as it may represent the total error for the datas. Whereas the mean of the normal represent the mean of error for the whole points that been marked (Lyew, 1998). The total and the error mean of the normal are calculated but in term of solving this, the tangent equation has to be generated in order to induce normal equation.

Tangent equation can be represented by applying the formula given below (Bradley and Smith, 1999):

$$
y_{t}(x)=\left(x-x_{0}\right) f^{\prime}\left(x_{0}\right)+f\left(x_{0}\right)
$$

Given $\mathrm{x}_{0}$ is the value of $x$ on the curvature. Normal equation can be constructed using the value of the slope for normal line, $\mathrm{m}_{\mathrm{n}}$ and the slope for the tangent line, $\mathrm{m}_{\mathrm{t}}$ by the formula given below (Bradley and Smith, 1999):

$$
\mathrm{m}_{\mathrm{t}} \mathrm{m}_{\mathrm{n}}=-1
$$

The summation of normal will represent the total error given by:

Error, $\mathrm{d}=\sqrt{\left(\mathrm{x}_{1}-\mathrm{x}_{0}\right)^{2}+\left(\mathrm{y}_{1}-\mathrm{y}_{0}\right)^{2}}$

Where $\left(\mathrm{x}_{0}, \mathrm{y}_{0}\right),\left(\mathrm{x}_{1}, \mathrm{y}_{1}\right)$ are the points of intersection of normal line and the tangent line (Bradley and Smith, 1999). 


\section{RESULTS AND DISCUSSION}

In reference to data tabulated in Table 2 and 3, the comparison between actual teeth and the cubic spline conformation recorded a total range of 3.841704 with average range of 0.320142 . Comparison with ellipse conformation gives a total range of 9.1700751 with an average of 0.7641729 while the comparison with parabola is known to have a total range of 5.2811617 with average of 0.4400968 . On the other hand, comparison between actual teeth conformation and catenary equation produces total range of 9.938044 with average of 0.82817 . It is verified that cubic spline conformation recorded the least range.

The range is calculated based on the distance between respective points on the two teeth conformation. For instance, in order to calculate the range between catenary equation and actual teeth conformation, the latter will undergo reflection and translation to correspond with the catenary. Subsequently, all normal at the 10 points from actual teeth data is determined. Tangent equation need to be solved first in order to obtain normal. Normal is required as it can deduce the shortest distance between two points. This shortest distance is measured as range.

\begin{tabular}{ll}
\multicolumn{3}{l}{ Table 2: The normal equation at different points } \\
\hline Value $\mathrm{x}_{0}$ & Normal equation, $\mathrm{y}_{\mathrm{n}}$ \\
\hline-3.7 & $\mathrm{y}_{1}(\mathrm{x})=-0.33576 \mathrm{x}-0.84219$ \\
-3.2 & $\mathrm{y}_{2}(\mathrm{x})=-0.36501 \mathrm{x}+0.681488$ \\
-2.6 & $\mathrm{y}_{3}(\mathrm{x})=-0.54846 \mathrm{x}+1.826783$ \\
-2 & $\mathrm{y}_{4}(\mathrm{x})=-4.55261 \mathrm{x}-5.20523$ \\
-1.2 & $\mathrm{y}_{5}(\mathrm{x})=-1.16424 \mathrm{x}+2.502908$ \\
-0.6 & $\mathrm{y}_{6}(\mathrm{x})=-0.75245 \mathrm{x}+4.348528$ \\
0.7 & $\mathrm{y}_{7}(\mathrm{x})=1.893615 \mathrm{x}+3.474466$ \\
1.8 & $\mathrm{y}_{8}(\mathrm{x})=1.857371 \mathrm{x}+0.956731$ \\
2.7 & $\mathrm{y}_{9}(\mathrm{x})=2.548247 \mathrm{x}-3.08012$ \\
3.4 & $\mathrm{y}_{10}(\mathrm{x})=0.182338 \mathrm{x}+1.772973$ \\
3.6 & $\mathrm{y}_{11}(\mathrm{x})=0.18153 \mathrm{x}+0.538896$ \\
3.9 & $\mathrm{y}_{12}(\mathrm{x})=0.307933 \mathrm{x}-1.20237$ \\
\hline
\end{tabular}

Table 3: Error when comparing the actual teeth with cubic spline, eliptic, parabolic and catenary

\begin{tabular}{lllll}
\hline Points & $\begin{array}{l}\text { Cubic Spline } \\
\text { error }\end{array}$ & $\begin{array}{l}\text { Ellipse } \\
\text { error }\end{array}$ & $\begin{array}{l}\text { Parabolic } \\
\text { error }\end{array}$ & $\begin{array}{l}\text { Catenary } \\
\text { error }\end{array}$ \\
\hline-3.7 & 0.000000000 & 1.2589230 & 0.9811300 & 1.402966 \\
-3.2 & 0.111988878 & 0.9966000 & 0.6632160 & 1.328127 \\
-2.6 & 0.000000000 & 0.0866560 & 0.2754070 & 1.415165 \\
-2 & 0.193903751 & 0.3105900 & 0.2606970 & 1.000000 \\
-1.2 & 0.390286650 & 0.1295890 & 0.7171690 & 0.570118 \\
-0.6 & 0.000000000 & 1.5499840 & 0.1574200 & 0.060358 \\
0.7 & 0.858290259 & 1.0221600 & 0.1000640 & 0.013937 \\
1.8 & 2.058834593 & 0.6553470 & 0.0424940 & 0.154972 \\
2.7 & 0.000000000 & 0.4681560 & 0.1955370 & 0.578253 \\
3.4 & 0.191302981 & 0.4695000 & 0.1898740 & 0.469416 \\
3.6 & 0.037096521 & 1.0905570 & 0.7020910 & 1.029815 \\
3.9 & 0.000000000 & 1.1320130 & 0.9960640 & 1.914918 \\
Total error & 3.841704000 & 9.1700751 & 5.2811617 & 9.938044 \\
Average error & 0.320142000 & 0.7641729 & 0.4400968 & 0.828170 \\
\hline
\end{tabular}

\section{CONCLUSION}

This research highlights a few important conclusions. Firstly, in comparing the four different teeth conformation, cubic spline curve is verified to coincide with research objective as it recorded the least range and shortest distance, as well as closely identical to the perfect, smooth teeth conformation.

By using cubic spline method, several neutral points on normal, undamaged actual teeth are chosen and its position is fixed in order to form a better arrangement of teeth. Thus, these points will produce zero range when compared with a treated teeth arrangement. As a consequence, total range will be very low.

On the other hand, it is quite difficult to get a zero range for every point in comparing the parabola, ellipse and catenary. This is obvious from the range calculated during the research. The main reason would be that general equations formulated by the ancient mathematicians only take the maximum length and width of teeth frame into account, without considering the neutral points on the teeth arrangement.

\section{REFERENCES}

Biggerstaff, R.H., 1972. Three variations in dental arch form estimated by a quadratic equation. J. Dent. Res., $\quad$ 51: $\quad 1509-1509 . \quad$ DOI: $10.1177 / 00220345720510055101$

Bradley, G.L., K.J. Smith, 1999. Calculus. 2nd Edn., Prentice Hall, Upper Saddle River, N.J., ISBN: 0136601359, pp: 1056.

BeGole, E.A. and R.C. Lyew, 1998. A new method for analyzing change in dentalarch form. Am. J. Orthopedics, 113: 394-401. DOI: 10.1016/S08895406(98)80010-3

Chapra, S.C. and R.P. Canale, 2002. Numerical Methods for Engineers: With Software and Programming Applications. 4th Edn., McGrawHill, London, ISBN-10: 0072431938, pp: 926.

Cheney, E.W. and D.R. Kincaid, 2007. Numerical Mathematics and Computing. 6th Edn., Cengage Learning, Belmont, ISBN-10: 0495114758, pp: 763.

Currier, J.H., 1969. A computerized geometric analysis of human dental arch form. Am. J. Orthod, 56: 164-179. DOI: 10.1016/0002-9416(69)90232-2

Hechter, F.J., 1978. Symmetry and dental arch form of orthodontically treated patients. Dent. J., 44: 173184. PMID: 274300

Izard, G., 1927. New method for the determination of the normal arch by the function of the face, Int. J. Orthod., 13: 582-595. 
Mills, L.F. and P.M. Hamilton, 1965. Epidemiological Studies of Malalignment a method for computing dental arch circumference. Arch. Circumference, 35: 244-248.
Pepe, S.H., 1975. Polynomial and catenary curve fits to human dental arches. J. Dent. Res., 54: 1124-1132. DOI: $10.1177 / 00220345750540060501$ 